\title{
IMPLEMENTATION OF A COMMUNITY-BASED FAMILY-CENTERED PROGRAM IN PORTUGAL: A MULTIPLE CASE STUDY EVALUATION
}

\author{
Ana Teixeira de Melo and Madalena Alarcão \\ University of Coimbra
}

\begin{abstract}
Family-centered, community-based programs are particularly suited to support families with at-risk children or maltreated children and achieve family preservation or reunification. In these child protection and child welfare cases, assessment is of great importance to inform decision making. But the implementation of services to support the families change and its evaluation in real settings is not without challenges. The Integrated Family Assessment and Intervention Model (IFAIM) was designed to conduct assessment and intervention with multichallenged families with at-risk or maltreated children and support the activities of the child protection system. In this article, we describe a pragmatic, focused on improvement, action research multicase study of the process and outcome of IFAIM's first implementation. Multiple factors affected implementation, namely, factors related with the teams, the organizations, and the communities. An improved model of implementation based on the evaluation results is proposed. (C) 2012 Wiley Periodicals, Inc.
\end{abstract}

\footnotetext{
The present work was supported by a doctoral scholarship (SFRH/BD/39912/2007) attributed to the first author by the Foundation for Science and Technology, Portugal.

We thank all participating organizations and the professionals involved in this research project for their invaluable contribution.

Please address correspondence to: Ana Teixeira de Melo, Rua Camilo Vaz, n $45,3^{\circ}$ dto. centro, 4430-686 Vila Nova de Gaia, Portugal. E-mail: anamelopsi@gmail.com
} 


\section{INTRODUCTION}

Family-support and preservation services have a considerable history in helping families. These services are particularly useful for those living in high-risk conditions to help them effectively deal with hardship or even to strengthen in face of adversity (Berg, 1991; Manalo \& Meezan, 2000; McCroskey \& Meezan, 1998). Family-centered approaches may offer families a respectful, empowering, and strength-based support sustained in a collaborative stance (Allen \& Petr, 1998; Dunst, Boyd, Trivette, \& Hamby, 2002). On the other hand, community-based and home-based integrative clinical services informed by ecological and systemic theories may be especially suited to meet the needs of multichallenged families and help them minimize multiple risks while developing strengths and increasing protection for their children (Boyd-Franklin \& Bry, 2000; Lightburn \& Sessions, 2006).

Community-based and family-centered integrated services are sparse in Portugal and social services' interventions tend to be expert-driven and focused on deficits (Sousa, Ribeiro, \& Rodrigues, 2006). However, in recent years, there was a significant increase in the number of specialized centers named Centros de Apoio Familiar e de Aconselhamento Parental (Centers for Family Support and Parental Counseling), known in brief as CAFAP, designed to support at-risk children and their families. These centers are usually integrated in nonprofit, community-based organizations, although funded by the social security services. Unfortunately, they have been operating without a clear common framework or a family-centered orientation. Nonetheless, CAFAP have the potential to incorporate family-centered practices and to answer a call of support from the Portuguese child protection services (Melo \& Alarcão, 2009). The Portuguese child protection system is organized into three levels (Law 147/99 of 1 of September). At the first level, one can find the child welfare services and all community organizations capable of providing some sort of the family and child support. The second level integrates the child protection services, which, in Portugal, are official, nonjudicial institutions that intervene to promote children's rights and protect children in danger, with parental consent. Child protection services have restricted Comissions, which are groups of professionals assigned for investigations and case management in child protection cases of endangered children and integrate at elements from different community institutions. The court level, or the third level of action, is assisted by a multidisciplinary court advisory team from the social security services. In the last years, evaluations of the child protection services have highlighted their difficulties in conducting assessments and in supporting families (CNPCJR, 2009).

The Integrated Family Assessment and Intervention Model (IFAIM) was developed to address these needs. It is a community-based and family-centered integrative assessment and intervention model, specifically suited for the CAFAP (Melo \& Alarcão, 2011a). IFAIM aims to provide collaborative and strength-based interdisciplinary integrated services to multichallenged families with at-risk, abused, or neglected children and to conduct assessments in child protection cases. It represents an integration of clinical, social, educational, and community work with forensic/child protection concerns.

This article describes an action research, pragmatic, and process and outcome multiple case study evaluation of the first implementation of IFAIM in local communities in Portugal. 


\section{A BRIEF OVERVIEW OF THE INTEGRATED FAMILY ASSESSMENT AND INTERVENTION MODEL STAGES}

IFAIM is organized in five stages: (a) referral, (b) reception, (c) assessment, (d) support for change, and (e) follow-up and closure. Each of these stages has specific objectives and procedures, described elsewhere with more detail (Melo \& Alarcão, 2011a).

The referral stage is crucial to define the context, the purpose, and the scope of assessment and the roles of each professional or team working with the family. The referral is performed through a form designed to collect relevant information about the case. In the reception stage, the team meets the family to negotiate the terms of their collaboration and prepare the beginning of assessment. Assessment in IFAIM has a collaborative orientation and the team tries to facilitate and support the family's change from the first contacts. This stage incorporates a risk and a comprehensive assessment and an assessment of the family's potential for change, (Hamilton-Giachritsis, Peixoto \& Melo, 2011). These assessments aim to inform tailor-made family support plans to facilitate change and help the families promote their children's safety and well-being. An assessment report is prepared at the end for the child protection services and the courts, when applicable. The recommended time for the assessment stage is 3 months. Some cases may continue to benefit from integrative support in a support for change stage, which lasts about 9 to 12 months. A follow-up period, from 6 months to a year, may precede case closure.

\section{EVALUATION RATIONALE AND DESIGN}

The design of this research study changed during the implementation of IFAIM. A pretestposttest, multiple-site evaluation was originally planned to assess the efficacy of IFAIM. We assumed that within a 9-month period of training, CAFAP teams could be prepared to implement IFAIM with fidelity so its outcomes could be evaluated. However, this did not happen. The conditions for the implementation and the adjustment to IFAIM were very different from site to site. A few months after the training of the first teams ended, and beginning case supervision, it was clear that the teams still had not mastered all the core skills to implement IFAIM. The implementation process seemed to be affected by different factors which we aimed to understand. It was clear that despite our preliminary efforts to develop a solid program and good materials, we still needed to learn how to improve it and make it both practical and useful in real contexts (Finne, Levin, \& Nilssen, 1995) without losing sight of its core features. At that stage we didn't know which obstacles should be overcome or which conditions could facilitate IFAIM's implementation.

Therefore, we decided to adopt an action research (Finne et al., 1995), mixedmethods, but predominantly qualitative (Patton, 2002) multiple case study design (Yin, 2009) evaluation. We privileged a pragmatic, utilization-focused orientation (Fishman, 1999; Patton, 1997). At a given point it was important to confirm and expand the experience and the results obtained with the first group. The inclusion of other teams and sites would improve the study's ecological validity and enrich the analysis. Therefore, a second group began their training approximately 3 months after the first group had finished theirs. Cycles of action-reflection-action were repeated throughout the course of this research study during approximately $21 / 2$ years. The first author assumed multiple roles (program developer, trainer, supervisor, and evaluator) during different moments of the action research process. The whole process was periodically discussed with the second 
author, who was not directly involved with the teams or the implementation process and could therefore look for different interpretations from different perspectives.

\section{PARTICIPANTS}

Eleven teams initiated collaboration with this research project (six in a first group, five in a second group). Two of the teams of the first group of six dropped out during the initial training period (for lack of funding and failure to meet all training requirements) and will not be further mentioned. The four remaining teams (A, B, C, and D) were all part of CAFAP, which are integrated in nonprofit private social organizations in northern and central regions of Portugal. Four teams of the second group were part of CAFAP. One team completed the initial training but due to the lack of funding to open CAFAP, it was forced to abandon this research project. Another team was invited to terminate collaboration during training due to failure to complete several of its core components. The remaining three teams (E, F, and G) were located along the rural southern, central, and northern coasts of Portugal. Written informed consent was obtained from all organizations and participants. The teams, all except one, were funded by the social security services and had a minimum of three professionals (a social worker, a psychologist, and a social educator), with the exception of the F team, which had only two. The financial agreement with the social security services was quite different in regard to the minimum number of clients to which the teams should provide services to be funded. Team $\mathrm{F}$ had a contract with the Social Security to support 20 families per year. Teams A, B, and G had to support 60, 40, and 55 children and their families per year. Teams $\mathrm{C}, \mathrm{D}$, and $\mathrm{E}$ had to provide services to $40(\mathrm{C})$ and $80(\mathrm{D}, \mathrm{E})$ children and their families per month.

\section{DATA COLLEGTION AND DATA ANALYSIS}

The first author adopted the role of a qualitative bricoleur researcher (MacLeod, 2001), choosing different methods according to the research questions and the information that emerged throughout the research process, following an iterative process to confirm previous analysis (Huberman \& Miles, 1994). Table 1 resumes data collection procedures, namely, methods, sources, and data retrieval. A database was organized for this study (Yin, 2009).

During implementation, the first author identified a certain number of outcomes and factors constraining or facilitating IFAIM's implementations. The contents of those observations and reflections and their meaning were organized in an attempted model aiming to improve IFAIM's implementation process and outcomes. The conclusions of this work were validated by the teams and the community partners in focus groups. All the focus group sessions were transcribed and the qualitative information was added to the one collected through the open-ended sections of the questionnaires used. A generic approach to qualitative analysis (MacLeod, 2001) was preferred, though integrating contributions from specific techniques, such as the constant comparison method (LaRossa, 2005). After several readings of the transcribed material, the first author identified the greatest possible number of thematic categories. After that, she identified main order and second order themes and organized the data accordingly. A final analysis looked for relations between the identified categories. This analysis highlighted core aspects of the implementation and provided a structure to organize the description of the process and outcomes of the implementation in the following sections. Except for the open-ended sections, the 







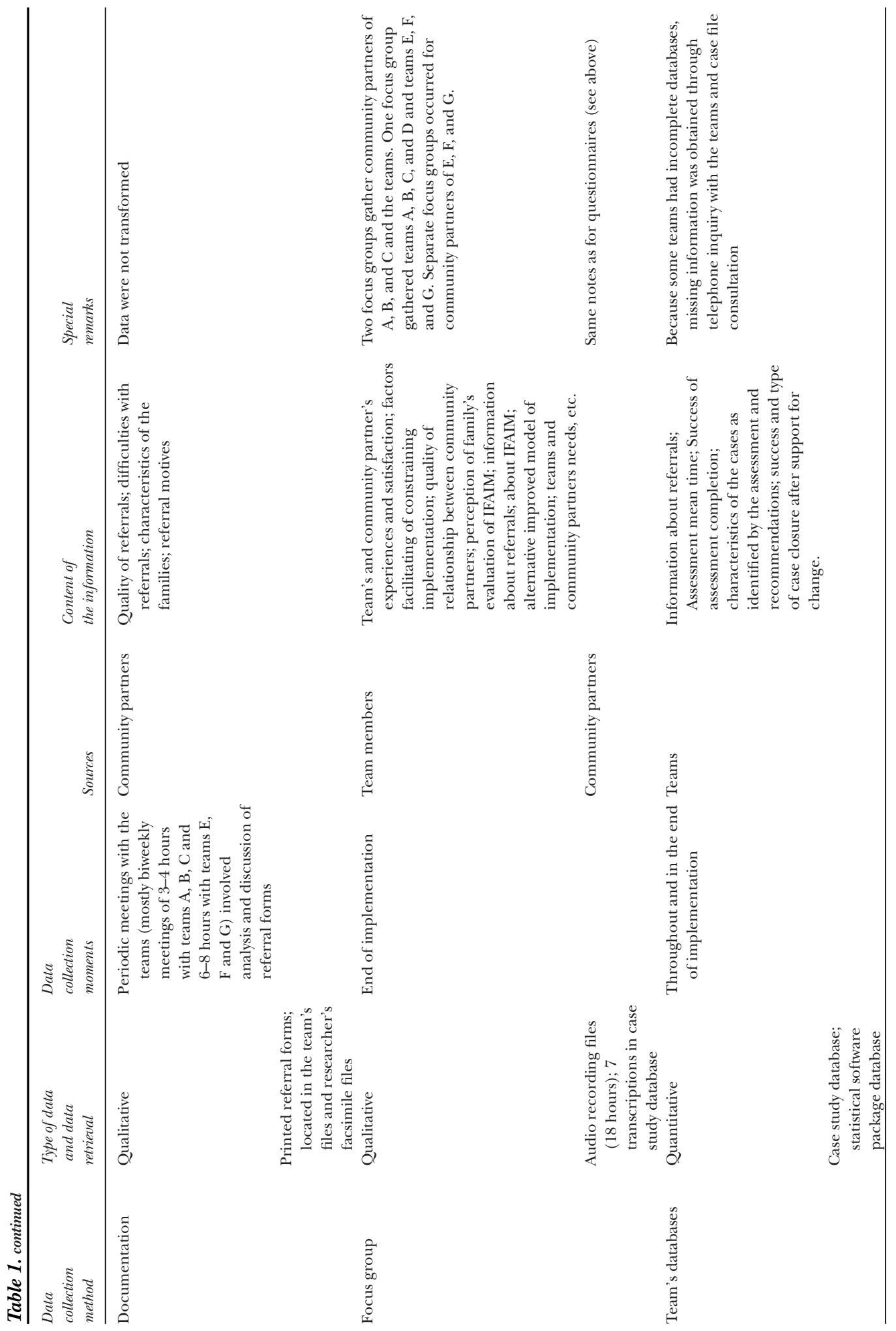


questionnaires used to obtain information from the teams or the community partners (Table 1) relied on 5-point Likert-type scales, ranging from 1 (very much/completely/great) to 5 (none/not at all). The results reported use this scale.

\section{STAGES OF IMPLEMENTATION}

The implementation of IFAIM was performed through different stages which we describe in the following sections as well as the team's initial conditions.

\section{Preimplementation Conditions and Preparation Period}

Teams A and E had only recently opened their services when this research project began and therefore planned their activities to integrate IFAIM. By the time their training began, teams $\mathrm{A}$ and $\mathrm{E}$ were operating for 9 and 11 months, respectively, while all the other centers were operating for $3(\mathrm{G}, \mathrm{C}), 4(\mathrm{D}), 5(\mathrm{~B})$, and 7 years $(\mathrm{F})$.

Although for some teams there was a lot of $(\mathrm{F})$ or some continuity, there was also rupture $(\mathrm{B}, \mathrm{D}, \mathrm{G})$ between the old model's theoretical assumptions, practical procedures, and techniques and those of IFAIM, for one (C) IFAIM represented a complete rupture with their previous working models.

For all teams, except for D and F, IFAIM's implementation replaced a previous equivalent approach, implemented IFAIM as a pilot experience, maintaining other services as usual. We used the organization's self-assessment and the collected observational data to classify the teams in regard to their conditions for the implementation of IFAIM (physical, organizational, etc.). Teams A, C, and E had excellent conditions, B and F had reasonable conditions and $\mathrm{D}$ had poor conditions.

\section{Initial Training and Pilot/Informal Implementation}

The teams had to conclude an initial 9-month training to implement IFAIM. The process and outcomes of this training are reported elsewhere (Melo \& Alarcão, 2011b). After the third month of training, which was focused on the referral stage, the teams informally presented IFAIM to their community partners in all levels of the child protection system, providing them a first version of the referral form. During the training the teams had to practice skills in real sessions with families so they informally began implementing IFAIM.

\section{Training for Community Partners: Formal Presentation of IFAIM and the Referral Process}

Shortly after the end of the initial 9-month training, a session was prepared for the teams' community partners to formally present IFAIM and introduce the referral process. The content of that session which is described in a manual, available with the authors, was previously approved by the National Commission of Protection of Children and Youth at Risk. Sessions were organized for community partners of teams A, B, and C together, and for site $\mathrm{D}$ separately. There was a repetition of the training 6 months later in site $\mathrm{C}$, because of reduced participation in the previous session. The content of the session was slightly altered for the sites E, F, and G to include a small lecture about IFAIM's assessments. A total of five training sessions were conducted reaching 75 professionals from different community institutions, the child protection services, and court advisory teams. At the end of those sessions, the majority of the participants $(60.9 \%)$ were quite willing to complete the referral form, and a smaller percentage $(29.7 \%)$ was 
very much willing to do it. The theoretical background of IFAIM was very much $(34.4 \%)$ or quite $(57.8 \%)$ appreciated. Most of the participants considered the IFAIM's proposal of role division and articulation between professionals working with the families to be quite appropriate $(57.8 \%)$ or somehow appropriate $(34.4 \%)$. Most of the participants considered the implementation of IFAIM in their community to be very much $(56.3 \%)$ or quite appropriate $(39.1 \%)$.

Before these sessions, teams A, B, C, and G considered the referrals to be poor, while teams $\mathrm{E}$ and $\mathrm{F}$ evaluated referrals as being more or less satisfactory. Team D had no referrals to IFAIM up to that point.

\section{Formal Implementation of IFAIM}

Formal implementation of IFAIM began after the presentation session for community partners and the end of the teams' initial training. Team D never concluded the training and, therefore, formal implementation did not take place. Six and 12 months after the beginning of formal implementation of IFAIM, we organized an assessment meeting/focus group with teams A, B, and C and their community partners, although no community partner from $\mathrm{C}$ participated. After the first meeting, the teams had supervised practice meetings with the first author for a period of 6 months until about the time the second group finished their initial training. During the 12 months, IFAIM's manuals, procedures, instruments, and forms were continuously revised and improved with the teams' feedback. The implementation of IFAIM in teams E, F, and G reflected some of those improvements. Separate focus groups with community partners were conducted in sites E, F, and G, again 6 months after the beginning of formal implementation. Those meetings were also used to elucidate the community partners of aspects of IFAIM that were not clear to them and to perform small lectures on different topics as needed. This was felt as particularly helpful for those professionals who didn't attended the training session for community partners. Problem-solving strategies in regard to particular aspects of the local implementation of IFAIM and relationship between community partners were also discussed. A focus group was conducted with each group of teams to assess their perspective and experiences at the end of implementation (12 months for sites A, B, and C and 6 months for sites E, F, and $G)$.

\section{PROGESS EVALUATION AND FACTORS FACILITATING OR CONSTRAINING IMPLEMENTATION}

In the following sections we report the results of the process evaluation in regard to different dimensions of IFAIM's implementation.

\section{Logistic and Organizational Support}

Throughout the implementation the teams experienced different levels of support from their organizations. Not only the adequacy of the logistic conditions influenced the implementation of IFAIM as the different leve'ls of autonomy and freedom the teams had within the organization seemed to influence their ability to perform the necessary changes to accommodate IFAIM's recommendations. Considering the researchers' observations and the organizations' self-assessment, we classified the teams in regard to (a) their flexibility to introduce internal changes in rules and procedures and the weight of bureaucracy, (b) 
the teams' degree of autonomy and the efficacy of the communication with their superiors, and (c) the level of knowledge or involvement of the teams' hierarchical superiors in IFAIM's implementation. These dimensions were used to classify the organizational setting as (a) very much positive (sites A, E, F, and G), (b) quite positive (site C), (c) somehow positive (site $\mathrm{B})$, and (d) and not positive (D).

\section{Experiences and Satisfaction of the Teams, Organizations, and Community Partners}

At the end of implementation, the teams/organizations B and G reported being very much satisfied with it, while teams A, D, E, and F were quite satisfied and team $\mathrm{G}$ was only somehow satisfied. IFAIM seemed to fit some teams' needs (C, F, G; e.g., team G: "IFAIM came in a time we were questioning the model of intervention who were using"). In sites $\mathrm{B}, \mathrm{D}, \mathrm{E}, \mathrm{F}$, and $\mathrm{G}$, the implementation contributed very much to a greater sense of achievement and involvement of the teams with their work, while teams $\mathrm{A}$ and $\mathrm{C}$ considered there was quite an improvement. On the other hand, teams A, B, D, E, and $G$ felt that their sense of security and competence in their work very much improved, while for teams $\mathrm{C}$ and $\mathrm{F}$, there was quite an improvement. In sites B, E, F, and G, the implementation of IFAIM was associated with a great improvement in the quality of the services provided and to the recognition of the teams' work by community partners. Teams $\mathrm{A}$ and $\mathrm{C}$ considered there was quite an improvement in this regard, but while the former indicated that IFAIM contributed a lot to the recognition from the community, the latter considered there was little contribution. The implementation of IFAIM triggered a deep restructuring in the CAFAP in B and C (team C: "In our organization everything changed. Even the former activities ended").

Some teams (B, F, G) mentioned that IFAIM made them work as a team and valued its interdisciplinarity: team B: "IFAIM forces us to think together ... and reach a consensus"; team G: "Before [IFAIM] there was the psychologist, the social worker, the social educator ... now we really work as a team."

The focus groups revealed overall positive evaluations of IFAIM in all the sites where it was implemented. Globally, IFAIM was valued by the teams (A, B, C, E) and their community partners (CPs; B, E, F, G) for being a structured, coherent, systematic, rigorous, reflexive, and intentional approach $(\mathrm{CP}$, site E: "It is a much more organized approach"; CP, site G: "It has structured and given consistency to their [the teams'] work). CPs in all sites mentioned IFAIM provided them with a greater sense of "security," which helped them to make decisions (CP, site E: "Knowing that a family can be supported by IFAIM's team gives us great security when deciding to support parents"; CP, site F: "The way they work offers security to whom makes referrals"). The work in IFAIM was considered quite distinct from that of other local services.

\section{Referrals}

During the formal implementation period, all teams had new cases referred to IFAIM, for a total of 67 families. Distribution of cases per team ranged from 4 (F) to 16 (A). Team B had 14 cases, team $\mathrm{E}$ and $\mathrm{G}$ had 12 cases each and team $\mathrm{C}$ had nine cases. Most cases were referred by child protection services $(56.7 \%)$ or court advisory teams $(23.9 \%)$, although in a different proportion from site to site.

For most sites (A, B, E, F), there were only some improvements in the referrals since the training for community partners. Although team $\mathrm{G}$ considered there to be quite an improvement in the quality of referrals, team $\mathrm{C}$ considered there to be little. 
Different difficulties were observed in regard to the referrals, namely, lack of information, poor quality of information, and paucity of referrals $(\mathrm{C})$. The referral form was revised during the implementation, particularly after the first focus group, to assist community partners in specifying the requested information. Still, for many cases, and in many sites, concerns remained: (a) cases were referred without any form, (b) fields on the form were left blank or poorly answered, and (c) cases were referred without meeting inclusion criteria in regards to the child's immediate safety.

\section{Factors Constraining and Facilitating Referrals and the Relationship Between Community Partners}

The main difficulties identified with the referrals where discussed with the teams and the community partners. Different strategies where developed by the teams to overcome them. In site $\mathrm{C}$, the poor quality of the relationship with the child protection services prior to the implementation of IFAIM seemed to negatively influence the referrals. It is possible that more mediation and support from the researcher could have facilitated cooperation. In site C, most of the cases were referred to services as usual instead of IFAIM. In this site, the implementation aggravated previous difficulties in the relationship between community partners.

Teams E and F reported that IFAIM progressively gained credibility among community partners despite some initial suspicion. However, most teams agreed that the implementation was too detached from the community for the community partners to be sufficiently involved to understand the implications of its work or respond to its calls. This seemed to be particularly aggravated by the fact that IFAIM's orientation was opposed to the dominant practices, which were expert-driven, uncollaborative, focused on deficits and on individuals (A, B, C, E, G). In several sites (B, C, E, G, F), community partners complained about the length of the referral form and the nature of the information required by it (A, B, G, F). Many considered they had an excessive volume of cases (A, B, E, F, G) and little time to do the necessary reflection and case analysis (B, F, E, G) required to fill the form.

The lack of facts in the referral forms was often problematic. Several community partners and teams agreed that partners were, in general, ill prepared to conduct prereferral assessments (identifying inclusion and exclusion criteria, conducting safety assessments, and implementing safety plans; A, B, E). Failure to participate in the training sessions for community partners (A, B, E, G), staff turnover (E), or early referral before the training sessions (A, B, E, G) were factors constraining the quality of referrals. Other difficulties in the relationship between community partners and the IFAIM team had to do with role clarification (A, B, C) and perturbations in communication $(\mathrm{C})$.

Strategies used to overcome barriers included prereferral contacts between community partners and the teams (A), postreferral meetings (A, B, C, E, G), and others aiming to improve collaboration (A). Other facilitating factors included a personal willingness "to do a good work," positive expectations, and detailed knowledge about IFAIM to "believe in it" (A, B, C, F, G).

Constraining factors included the lack of feedback for community partners about the quality of their referrals $(B, G)$. All teams felt unprepared to elucidate and support community partners because they were still learning to master IFAIM. They considered that IFAIM's complexity and their limited capacity and experience during their training period and the first months of implementation favored the emergence of poor practices, 
which were hard to change afterwards. The teams considered they could have benefited from a greater involvement and knowledge of the community partners about IFAIM.

\section{Assessment and Support for Change}

By the end of the implementation, assessments were ongoing for several cases $(16.4 \%)$, while other cases had earlier closures due to the inadequacy of the referral to IFAIM $(11.9 \%)$. Assessments that were completed with success $(40.3 \%)$ were performed within a mean period of 4.63 months (standard deviation $[S D]=1.94$; minimum $=1$; maximum $=9$; mode $=4)$. CPs in some sites $(\mathrm{B}, \mathrm{G}, \mathrm{E})$ associated IFAIM with an increase in the quality of assessment and intervention (CP, site G: "one can see the difference") and identified gradual improvements in the quality of the teams' work (B, G, E). Only one community partner $(\mathrm{G})$ had a global negative evaluation of IFAIM, considering it to be too "complicated" and "long." However, that element later admitted being misinformed about IFAIM.

Some teams evaluated their assessments to be consistent and organized (E, F). The quality of assessments and the reports were particularly valued by the community partners (A, B, E, F, G, ), which classified them as "rigorous" (CP, site F: "It's not common sense, they know what they are talking about"), "in-depth and rich" (CP, sites E, G), and as providing a detailed account of the families' experiences and the work developed with them (CP, site B: "A better understanding of the cases"). The quality of the reports and their utility in informing decisions was appreciated (CP, site A: "When we receive one of these [IFAIM] reports it is much easier to make a decision about which action to take") because it increased their sense of "security" (A, B, E, F, G). IFAIM made it less difficult for child protection services to remove a child from the home because the family could be supported to achieve reunification (CP, site B: "We can continue to work with the family. It makes it easier to propose it ... the family had this preparation, it was not a perceived as a punishment"). The assessments were valued for being more useful than traditional psychological forensic assessments because of their broader scope and the clear linkage with interventions (E, G). There were positive expectations regarding the assessment of the families' potential for change assessment (CP, site G: "The assessment of the potential for change is very meaningful for the courts ... this can mark the difference from other teams") and elucidation of the conditions to change (CP, site G: "In IFAIM cases I think the greatest change [in comparison with other approaches is] understanding which dimensions really make the [family] change"). Negative aspects include the length of the reports (B) and delays in the conclusion of assessment $(\mathrm{G})$.

Several community partners (A, E, C, F) valued IFAIM's collaborative stance: CP, site $\mathrm{E}$ : "There is a different way of looking at people's capacities ... it is focused on their wills, initiatives, strengths, and works from them"; CP, site F: "They really respect you [the team]"; CP, site E: "This teams works with the family as if another partner"). There were examples of "difficult" cases in which the family's involvement surpassed expectations: CP, site G: "[A lady] was really resistant ... I thought she would have the same behavior as all other professionals and that was overcome [by the IFAIM's team]. Benefits were identified for families participating in mandated assessments: CP, site A: "I think they [the parents] felt the intervention made them reflect upon and rethink their way of living"; CP, site F: "They realized they had limitations. Without learning that they could not change." Some of the community perceived that the families were thoroughly informed about what was expected of them regarding the child protection system, about their rights and duties and 
the role of each professional (CP, site E: "I have noticed that families really know the role of each professional involved ... they know they have tasks to complete ... they know when they should inform us about something").

According to community partners (A, B, E, F, G), IFAIM made a general positive contribution to the families' change: CP, site A: "I have no doubts about it [positive contributions for change]"; CP, site F: "[Before IFAIM] we ended up not doing much for the family"; CP, site E: "We [community] are now much more prepared to work with the families"; CP, site E: "It [the team] can get into these families and perform changes from inside-out."

We found reports of unexpected positive results of IFAIM in supporting the family change: CP, site E: "I remember receiving the [positive] feedback for a case, and we were not going to invest in them [the parents] anymore!". Gains were also identified in unsuccessful cases: CP, site A: "It doesn't mean all cases are successful but I think that in all there have been some gains"; CP, site E: "Even when things don't go that well ... the family still gets a positive feeling ... there are positive results." The teams $(\mathrm{C}, \mathrm{F}, \mathrm{E}$, G) evaluated the results as positive and quick: team B: "We [now] provide a much better service to the families"; team F: "we can see much better results, more quickly".

\section{OUTCOME EVALUATION}

The implementation of IFAIM was completed with success in sites A, B, C, E, and G, where IFAIM became a core service following all main recommendations. In site $\mathrm{F}$, the implementation was completed but IFAIM is not a core service. Although it will have continuity, the teams and organizations stated that some but not all recommendations will be adopted. In site $\mathrm{D}$, the implementation failed. Nevertheless, some aspects of IFAIM (e.g., procedures, instruments) were incorporated in the teams' work. In sites A, C, D, E, and $\mathrm{G}$, the organization was interest in training new professionals as needed. However, in sites $\mathrm{B}$ and F, IFAIM is adopted insofar as the current team remains in the organization. Organizations B, D, E, and G considered contracting supervision only if their contract with social security services covered the costs, which was not happening. In F, the organization intends to seek financial support.

According to observational data, the first author classified the fidelity of implementation regarding basic procedures (e.g., completion of recommended tasks and objectives; adequate use of core forms and instruments; timings, etc.). Only team A was evaluated as accomplishing all or almost all basic procedures or doing it for most of the cases. Teams C, E, and F fulfilled a lot of the procedures, but not all, for many cases, but teams B and $\mathrm{G}$ accomplished only some of the procedures or only for some cases.

The teams classified their cases at the end of the assessment stage in regard to the degree of success in accomplishing assessment objectives and the elaboration of an assessment report. Assessment was considered successful if it was completed as planned, provided answers to inform decision making, contributed to the definition of a support project for family preservation or reunification, or to alternative placements to guarantee the children's safety and well-being. Assessment reports were elaborated for all cases of child protection.

Excluding the ongoing cases and those not indicated for IFAIM. The teams concluded the assessments with success for $55.1 \%$ of the cases. Teams A and E had the highest proportion of assessments completed with success. By the end of implementation, most of the cases that entered the support for change stage were still ongoing. 


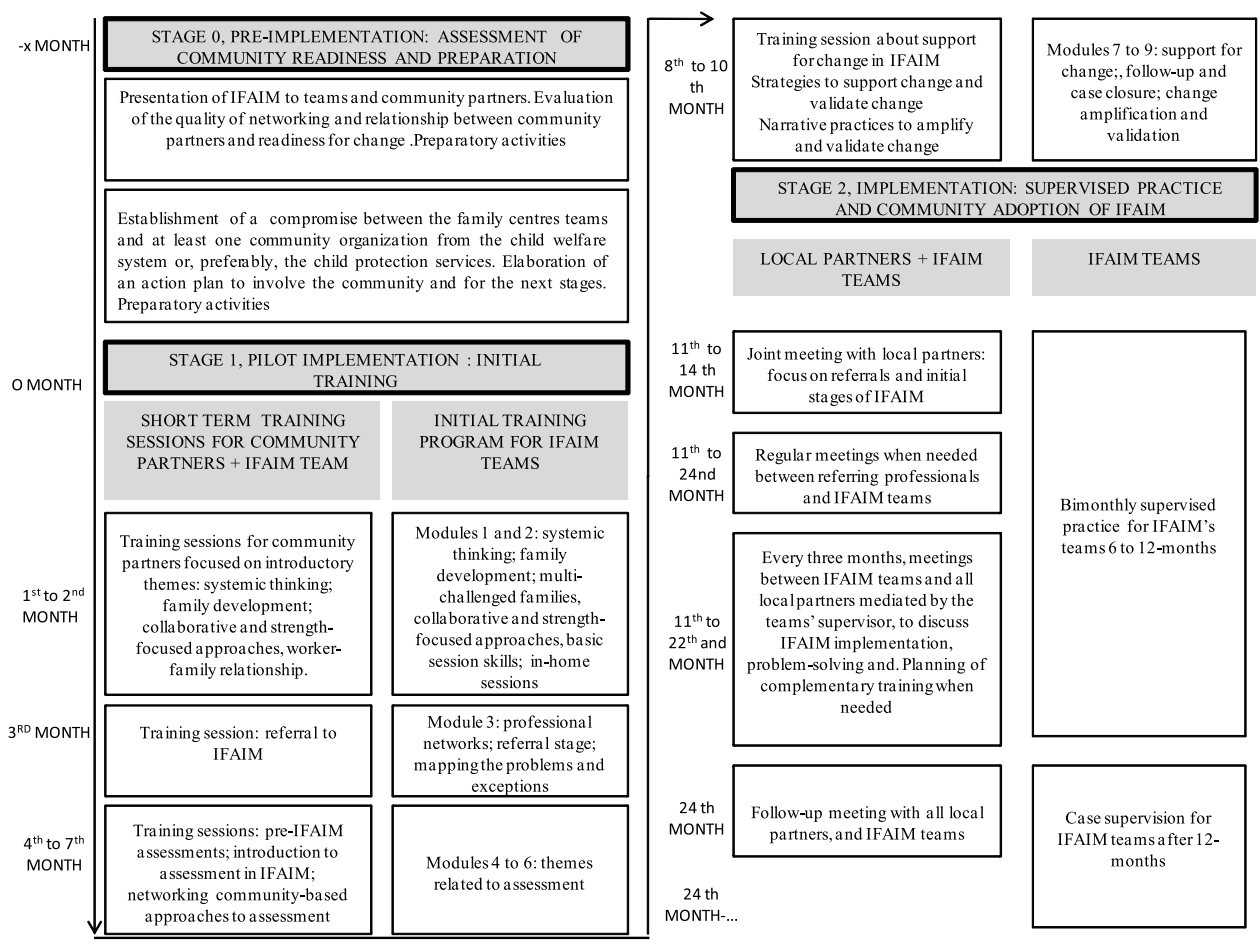

Figure 1. Revised model of the implementation of IFAIM.

\section{A REVISED MODEL FOR THE IMPLEMENTATION OF IFAIM}

Throughout this research study, changes were made in IFAIM and in the implementation process. Notwithstanding those improvements and the overall general positive evaluation of IFAIM's contributions, many factors impaired the quality of its implementation. Factors specifically associated with the teams' training are described elsewhere (Melo \& Alarcão, $2011 b)$. Throughout the implementation the researcher identified other common and unique factors that could facilitate or constrain the implementation and discussed them with the teams. In this process, through qualitative inquiry and analysis, a provisional theory of change emerged to give place to an improved model for the implementation of IFAIM, which incorporates many of the teams' and their community partner's suggestions. This revised model for the implementation of IFAIM aims to overcome obstacles associated with the characteristics of the organizations and the professionals, the referrals, the dynamic of local communities, and the relationships between community partners. This proposed process of implementation is organized in three stages as depicted in Figure 1.

The main purpose of this revision is to promote community and organizational readiness and a more shared process of co-construction and joint learning between community partners throughout implementation (Edwards, Jumper-Thurman, Plested, Oetting, \& Swanson, 2000). This model may contribute to overcome many problems associated with the referrals and constraining factors at the level of the organizations and their relationships with community partners, aiming to increase their joint capacity (Goodman, 2000). The training for community partners will be extended to all professionals working in social organizations because they are likely, at a given point, to integrate the child 
protection services. The child protection services should be involved as a core partner of the IFAIM teams to stimulate the participation of the greatest possible number of community partners and collaborate in an action plan to accomplish stages one and two.

\section{CONGLUSION}

This research study aimed to describe and evaluate the process and outcome of the implementation of a family-centered, multisystemic, collaborative, and strength-focused family assessment and intervention model in local communities in Portugal. This model was designed to support multichallenged families with at-risk, abused, or neglected children as well as the child protection and welfare system. This action-based and pragmatic research revealed that it is possible to implement and disseminate such a program through university-community partnerships. The process was not without difficulties, but the results indicate an improved model of implementation. It shows that there are a number of variables related to the professionals, the teams and their organizations, the community, as well as the relationship between community partners, which may facilitate or constrain the quality of the implementation (Durlak \& DuPre, 2008). Therefore, it highlights some aspects to be attentive to when undertaking this kind of endeavor. Despite the difficulties, the results show evidence that, with favorable organizational and community conditions, it is possible to implement multisystemic, family-centered, collaborative, and strength-based programs with the characteristics of IFAIM in community-based family centers, even when the dominant approaches are opposed to such orientations.

Throughout the implementation, the teams were learning to master IFAIM and the necessary skills to implement it with fidelity. The results were broadly appreciated by not only the teams but also the community partners. IFAIM was associated with an improvement of the quality of the services provided by the teams and to positive gains for the families and the child protection system.

This case study has indicated that IFAIM may be a promising model and has potential to be successfully implemented in local community-based family support centers. Still, future research should consider evaluating implementations with the revised model and its outcomes in regard to its efficacy.

\section{LIMITATIONS}

This study has several limitations. Although a case study approach seemed adequate because of the lack of previous information about the phenomenon and the limited control the researcher had over the whole process, its descriptive nature is also a limitation because we cannot make causal statements linking the outcomes with the implementation process of IFAIM. Different methods, times of data collection, and informants were used but it wasn't possible, in some sites, to access some relevant informants, which limits the conclusions. The evaluator (the first author) has accumulated different roles, namely, the ones of program developer, trainer, supervisor and, evaluator. Personal bias may have influenced the implementation positively (e.g., the strong personal investment in supporting the teams; depth of the data collected) and negatively (e.g., constrained willingness to revise some aspects of the model and the implementation process). Because of great involvement and participation, it is possible that the first author's personal characteristics and the dynamic of the relationship with the teams influenced the results. The design of 
this study was altered after the first months of implementation when previous assumptions were proven to be flawed. The results could be different if a more flexible, emergent design and a discovery-oriented approach were adopted from the beginning. The culturally specific context may limit also the study's validity.

\section{REFERENCES}

Allen, R. I., \& Petr, C. G. (1998). Rethinking family-centered practice. American Journal of Orthopsychiatry, 68(1), 4-15.

Berg, I. K. (1991). Family preservation: A brief therapy workbook. London, UK: BT Press.

Boyd-Franklin, N., \& Bry, B. H. (2000). Reaching out in family therapy: Home-based, shool and community interventions. New York, NY: The Guilford Press.

Comissão Nacional de Protecção de Crianças e Jovens em Risco [National Comission for the Protection of Children and Touth At-Risk] (2009). Relatório anual de avaliação das actividades das comissões de protecção de crianças e jovens [Annual report of evaluation of the activities of the comissions for protection of children and youth]. Lisboa: Author.

Dunst, C. J., Boyd, K., Trivette, C. M., \& Hamby, D. W. (2002). Family-oriented program models and professional helpgiving practices. Family Relations, 51, 221-229.

Durlak, J. A., \& DuPre, E. P. (2008). Implementation matters: A review of research on the influence of implementation on program outcomes and the factors affecting implementation. American Journal of Community Psychology, 41, 327-350.

Edwards, R. W., Jumper-Thurman, P., Plested, B. A., Oetting, E. R., \& Swanson, L. (2000). Community readiness: Research to practice. Journal of Community Psychology, 28(3), 291-307.

Finne, H., Levin, M., \& Nilssen, T. (1995). Trailing research. A model for useful program evaluation. Evaluation, 1(1), 11-31.

Fishman, D. B. (1999). The case for pragmatic psychology. New York, NY: NYU Press.

Goodman, R. M. (2000). Bridging the gap in effective program implementation: From concept to application. Journal of Community Psychology, 28 (3), 309-321.

Hamilton-Giachritsis, C., Peixoto, C. S., \& Melo, A. (2011). Risk: Assessment and Intervention. In T. Magalhães (Coord.), Abuse and Neglect Series, 1. To improve the management of child abuse and neglect (pp. 89-132). Porto: SPECAN.

Huberman, A. M., \& Miles, M. B. (1994). Data management and analysis methods. In N. K. Denzin \& Y. S. Lincoln (Eds.), Handbook of qualitative research (pp. 428-444). Thousand Oaks, CA: Sage.

LaRossa, R. (2005). Grounded theory methods and qualitative family research. Journal of Marriage and the Family, 67, 837-857.

Law 147/99 of 1 of September. Diário da República [Diary of the Republic], I Série- A, N. 204 , 1-9-1999, pp. 6115-6132.

Lightburn, A., \& Sessions, P. (2006). Community-based clinical practice. Re-creating the culture of care. In A. Lightburn, \& P. Sessions (Eds.), Handbook of community-based clinical practice (pp. 19-35). Cary, NC: Oxford University Press.

MacLeod, J. (2001). Qualitative research in counseling and psychotherapy. London, UK: Sage.

Manalo, V., \& Meezan, W. (2000). Toward building a typology for the evaluation of services in family support programs. Child Welfare, 79(4), 405-429.

McCroskey, J., \& Meezan, W. (1998). Family-centered services: Approaches and effectiveness. The future of children, 8(1), 54-71.

Melo, A. T., \& Alarcão, M. (2009). Centros de Apoio Familiar e Aconselhamento Parental: Proposta de um modelo global de organização. Psicologia \& Sociedade, 21, 1, 55-64. 
Melo, A. T., \& Alarcão, M. (2011a). Integrated Family Assessment and Intervention Model: A Collaborative Approach to Support Multi-Challenged Families. Contemporary Family Therapy, 33, 400-416.

Melo, A. T., \& Alarcão, M. (2011b). Training professionals in community settings: change processes and outcomes in a child protection context. Manuscript submitted to publication.

Patton, M. Q. (1997). Utilization-focused evaluation. The new century text ( $3^{\text {rd }}$ ed.). London, UK: Sage.

Patton, M. Q. (2002). Qualitative research and evaluation methods (3 ${ }^{\text {rd }}$ ed.). Thousand Oaks, CA: Sage.

Sousa, L., Ribeiro, C., \& Rodrigues, S. (2006). Intervention with multi-problem poor families: Towards a strengths-focused perspective. Journal of Social Work Practice, 20, 2, 189-204.

Yin, R. K. (2009). Case study research. Design and methods ( $4^{\text {th }}$ ed.). Thousand Oaks, CA: Sage. 